(C) Copyright 2018: Editum. Servicio de Publicaciones de la Universidad de Murcia. Murcia (Spain) ISSN print edition: 0212-9728. ISSN on line edition (http://revistas.um.es/analesps): 1695-2294. On line edition License Creative Commons 4.0: BY-NC-ND

\title{
The role of objective and subjective experiences, direct and media exposure, social and organizational support, and educational and gender effects in the prediction of children posttraumatic stress reaction one year after calamity
}

Sefa Bulut*

Ibn Haldun University (Turkey)

\begin{abstract}
Título: El papel de las experiencias objetivas y subjetivas, la exposición directa y mediática, el apoyo social y organizacional, y los efectos educativos y de género en la predicción de la reacción de estrés postraumático de los niños un año después del desastre.

Resumen: El propósito de este estudio fue evaluar el efecto de la exposición directa, indirecta, objetiva y subjetiva en el desarrollo del Trastorno de Estrés Postraumático (DEPT). El impacto del apoyo y la organización social, así como el efecto de la edad y el género, fueron examinados en relación con el desarrollo de DEPT en este grupo. Los participantes fueron 270 estudiantes de escuela elemental y secundaria sobrevivientes al desastre. Un año después, cada participante completó el Índice de Reacción al Trastorno de Estrés Postraumático (Children's Post-Traumatic Stress Disorder Reaction Index, CPTSD), exposición al trauma, apoyo social y la escala de apoyo organizacional. Los factores participantes se predijeron por medio de un análisis de regresión stepwise. Una combinación de puntajes de exposición directa, indirecta, objetiva y subjetiva, género, edad, apoyo social y organizacional explicó el $17 \%$ de los puntajes de DEPT. La exposición directa explicó un $6 \%$, la exposición indirecta el $5.4 \%$, edad $3 \%$, falta de alimento el $1 \%$, y tener un amigo que se cambió de lugar de vivienda después del desastre contribuyó en la explicación de un $2.6 \%$ de la varianza total. La exposición subjetiva y la exposición directa parecen ser los principales predictores. Sin embargo, contrario a los hallazgos de estudios anteriores, la exposición a los medios, el género y la exposición física aparecen como pobres predictores. $\mathrm{Ni}$ los daños a la escuela o a la casa, la muerte de familiares o amigos o la falta de acceso a servicios como el gas, el agua o la energía contribuyeron significativamente a los resultados.

Palabras clave: Predictores del TEPT en niños; apoyo social y TEPT; efectos de la edad y el género en el TEPT; grado de exposición y TEPT; exposición a los medios y la televisión y TEPT.
\end{abstract}

\begin{abstract}
The purpose of this study was to test the direct, indirect, objective, and subjective exposure effect on the development of Post Traumatic Stress Disorder (PTSD). The impact of social and organizational support, as well as age and gender factors, were examined in development of PTSD. Participants were 270 disaster survivor elementary and secondary school students. One year after the disaster, each participant filled out a Children's Post-Traumatic Stress Disorder Reaction Index (CPTSD), trauma exposure, trauma experiencing, social support, and organizational support scales. Male and female students were compared on these instruments with univariate Anova. Elementary school children outscored both on the organizational support and trauma scale and this reached significance level. Additionally, contributing factors were predicted with a stepwise regression analysis. A combination of direct, indirect, objective exposure scores, subjective exposure scores, gender, age, organizational and social support variables accounted for $17 \%$ of the PTSD scores. Direct exposure accounted for $6 \%$, subjective exposure $5.4 \%$, age $3 \%$, having a friend moving away $2.6 \%$ and food shortage contributed $1 \%$, and of the total variance. Direct exposure appeared to be the most significant predictors, followed by subjective exposure. Media exposure, gender, and physical exposure seemed to be especially poor contributors. Neither school nor home damage, the death of relatives or friends, or gas, water, and electric shortages contributed significantly to the results.

Keywords: Predictors of PTSD in children; social support and PTSD; Age and gender effects on PTSD; degree of exposure and PTSD; Media and TV exposure and PTSD.
\end{abstract}

\section{Objective and Subjective Experiences and Media Exposure in Development of Children's PTSD Reactions}

By definition, disasters are natural phenomena that can occur unexpectedly any time and any place. Throughout the ages, human beings have experienced numerous disasters and the expectation is realistic that there will be just as many more in the coming years. On a daily basis, there are reports of earthquakes, hurricanes, and flooding disaster news in TV, radio and other news media reports. In the psychological literature, there are a tremendous number of studies concerning the effects of trauma on the mental health of individuals. While early studies focused more exclusively on prevalence rates (Bulut, Bulut \& Tayli, 2005; Zhang, Shi, Wang \& Liu,

* Correspondence address [Dirección para correspondencia]: Prof. Dr. Sefa Bulut, Ibn Haldun University, Department of Counseling Psychology, Ulubatlı Hasan Cad. No:2, 34494 Başakşehir / İstanbul (Turkey).E-mail: sefa.bulut@ihu.edu.tr
2011), and gender and age differences (Bulut, 2009a; Zhang et al. 2011), the majority of recent studies are more concerned about risk and protective factors (Cheng, Wang, Wen \& Shi, 2014; Tuicomepee \& Romano, 2008; Wang et al., 2009; Zhang et al., 2011), resiliency (Heetkamp \& de Terte, 2015), symptom structure of PTSD (Bulut, 2009b; LeivaBianchi \& Gallardo, 2013), neurobiyological foundations of PTSD (Maia, 2010) and longitudinal effects of trauma (Bulut, 2010; Ruiz, 2006). While many studies have attempted to develop models for an explanation of the etiology and prognosis of PTSD, some studies also focused on effective treatment modalities (Habigzang, Freitas, Hohendorff \& Koller, 2016).

Typically, three types of models emerge when looking to multivariate models for the explanation of the development and maintenance of PTSD. The first group focuses on the traumatic event as the main source and cause of the traumatic reactions.

Pfeferbaum (2005) provided a comprehensive literature review concerning the stressor criterion for PTSD as it is ob- 
served in children. The stressor criterion has three major components; a) any traumatic event that may evoke traumatic symptoms, b) degree of exposure, and c) individual subjective reaction to the traumatic events.

a) The magnitude of the disaster, nature and severity of traumatic events (Bulut, 2010; Wang et al., 2009; Wolfe, Sas \& Wekerle, 1994; Zhang et al. 2011), the type and characteristics of the disaster (Bulut, 2003; Leiva-Bianchi \& Gallardo, 2013; Rubonis \& Bickman, 1991), and the number of traumatic events (Priebe et al., 2009) are the factors most often cited in the literature.

b) For the exposure; degree of exposure (March, AmayaJackson, Terry \& Costanzo, 1997; Tuicomepee \& Romano, 2008), dose of exposure (Bulut et al. 2005; Başoğlu et al. 2004; Cheng et al. 2014), high and low exposure (Bulut, 2006; Wang et al., 2009), direct exposure (Bulut 2010; Seino, Takano, Mashal, Helmat \& Nakamura, 2008), indirect exposure (Vila, Porche \& MourenSimeoni, 1999), indirect media exposure (Otto et al., 2007), print media exposure, broadcast media exposure (Pfeferbaum et al., 2003), emotional and television exposure (Pfeferbaum et al., 2001), physical exposure and indirect interpersonal exposure (Pfeferbaum et al., 2000), and objective exposure (Braun-Lewensohn, CelestinWestreich, Celestin, Verté \& Ponjaert-Kristoffersen, 2009) are all mentioned in defining the severity of the events an individual may experience in his exposure to a disaster or traumatic event.

c) Subjective reactions (Pfeferbaum, 2005) are an individual's perception and evaluation of the event called "subjective exposure"; especially during the disasters, for the most part fear (Heetkamp \& de Terte, 2015; Laufer \& Salomon, 2006) is investigated in the research studies. DSM-IV TR (APA, 2000) specifically requires the sense of fear, helplessness, and hopelessness that can be evoked by the disaster as one of the main epredictors of PTSD. Previous studies reported that the subjective experience of fear was more strongly related to PTSD than the objective exposure alone (Gavriovic, Lecic, Knezevic \& Priebe, 2002). Similarly, Terranova, Boxer, SheffieldMorris (2009) found that fear reactivity predicts more severe initial symptoms, but not later ones. Fear experienced during the disaster was a strong predictor of PTSD symptoms in adults (Başoğlu et al., 2004) and adolescents (Heetkamp, \& de Terte, 2015).

The second group of models focuses predominately on the social, peer and family supports and family functioning before or after the calamity. Wu, Chen, Weng, and Wu (2009) tested the traditional social support, supportive and detrimental social relations model and concluded that the detrimental social relation model is essential in recovering and adjusting to the post disaster area. Tuicomepee and Romano (2008) reported that family functioning and family support were protective factors in overcoming the psychological effects of a tsunami disaster. Similarly, Otto et al.,
(2007) mentioned the pre-event family support as the protective factor and children's perceptions of low social support and high conflict in family settings as the predictor of PTSD. There was a significant negative correlation between family member relationships, social support, and PTSD. In the absence of social support, or when it is perceived as not being supportive, PTSD symptoms increased (Cheng et al. 2014). Other studies investigated the role of social support in the prediction of PTSD in children three months after a hurricane disaster (Vernberg, LaGreca, Silverman \& Prinstein, 1996). Seven and ten months after the same disaster, a high degree of social support was found to function as a protective factor in children (LaGreca, Silverman, Vernberg \& Prinstein, 1996) and in adults (Cheng et al. 2014). Terranova et al. (2009) mentioned the importance of peer support as a protective aspect and, conversely, peer-victimization in predisaster events was found to be a risk feature for PTSD.

The third group of models is more influenced by economic models and thus focuses more on the financial and resource losses. For example, after an earthquake, Cheng et al. (2014) and Freedy, Saladin, Kilpatrick, Resnick \& Saunders (1994) reported resource loss as being an important predictor of psychological distress. Similarly, Seino et al. (2008) found food shortage during times of civil disturbance to be a significant predictor of PTSD. Similarly, Sanchez, Korbin, and Viscarra (1995) emphasized the lack of food, transportation, cleaning, laundry, childcare, and housing as instrumental and tangible supports, which have a significant effect on individual stress levels. Tuicomepee and Romano (2008) reported that family disruption and financial insecurity increase vulnerabilities in children. As summarized in post disaster situations, Garrison et al. (1995) believed that post disaster adversaries are or may be even more significant than the exposure and magnitude of the initial disaster. Wang et al. (2000) investigation of two Chinese villages that sustained different levels of exposure found that individuals in the low-level exposed village demonstrated more post traumatic symptoms because they did not have adequate financial resources or aid to repair their damaged houses. They concluded that the additive and interactive effects of harsh post disaster conditions and relatively insufficient social support accounted for the higher incidence of PTSD in the low impact village. In another study, Kun, Han, Chen and Yao (2009) pinpointed risk factors after a major catastrophe as including 1) a low household income, 2) living in a temporary refuge, and 3) having a damaged home. Similarly, Cheng et al. (2014) mentioned not having a regular income as one of the most predictive important factors. Thus, the authors believed that governmental and nongovernmental programs could provide social and economic supports for the disaster sufferers, which would alleviate the negative effects of the traumatic events.

While the early trauma studies focused mainly on the degree and severity of exposure and the type of trauma (Bulut et al. 2005; Bulut, 2006), the prevalence rates of PTSD (Bados, Greco \& Toribio, 2012; Bulut, 2009a, 2010), more re- 
cent studies focused on the phenomenology of the traumatic experiences (Bulut, 2009b; Ruiz, 2006), predictive factors (Wang et al., 2009), comorbid disorders (Başoğlu et al. 2004; Zhang et al. 2011), social and school problems (Bulut, 2013).

In her seminal comprehensive literature review, Pfefferbaum (2005) defined three types of exposure, which must be present for a $D S M I V$ criteria A diagnosis. Direct exposure involves physical presence, direct victimization, and witnessing of the traumatic events. Indirect exposure involves knowing someone who loses his or her life, gets harmed in some way, or has an interpersonal relationship with a direct victim. Exposure via media coverage involves watching and/or witnessing traumatic events on TV or via print media.

Braun-Lewensohn et al. (2009) argued that there is no unity in the conceptualization and operationalization of exposure to a disaster in the literature. They identified three types of exposure; objective, subjective and mixed exposure models. Direct physical exposure is considered the main factor in the development of PTSD and other emotional and behavioral problems. Research studies also mentioned exposure through a relationship with a victim commonly cited as indirect, interpersonal, or family exposure. Depending on the type, level, severity, and times of exposure, the more frequent and the higher the levels of events of an individual exposed to a disaster, the stronger the risk of an increased risk of PTSD.

In a most recent study, Kim et al. (2009) researched the effect of direct and indirect exposure to a fire-escape drill in which direct exposure is defined as having been witness to the incidents. In assessments at two days, two months, and six months, the direct exposure group had higher PTSD and other anxiety disorders. Vila et al. (1999) studied the direct and indirect exposure 18 months after they were taken hostage in their school. The direct exposure group demonstrated more symptoms; but the indirect group also showed some degree of stress and traumatic reactions. Bulut (2010) conducted a longitudinal disaster study with directly effected children and reported a "fluctuation pattern" of PTSD with 3 years independent measurement follow ups.

Otto et al. (2007) exclusively researched the effect of indirect exposure after 9/11 incidents via TV exposure. They concluded that even only indirectly witnessing the terrorist attacks via TV predicted the risk of PTSD. With PTSD rates reported at $5.4 \%$, there was a significant correlation between the amount of TV viewing and PTSD symptoms. Likewise, Pfefferbaum et al. (2001) investigated the impact of TV exposure seven weeks after the Oklahoma City bombing. The degree of TV exposure was found to be directly related to post traumatic stress and slightly contributed to the development of PTSD as well.

Pfefferbaum et al. (2003) compared the broadcast and print media exposure in children who had indirect interpersonal exposure to the Oklahoma City bombing two years after the incidents. Results revealed that printed media exposure was more strongly associated with permanent post traumatic stress than broadcast media exposure. The Pfefferbaum et al. (2000) study with children living in Oklahoma City identified media exposure and indirect interpersonal exposure as a significant predictor of symptomatology. They reported that children who are physically distant from a disaster (not experienced directly) and who did not know anyone killed or injured (in this case, in the bombing) can still report PTSD symptoms and other functional difficulties, which can be directly attributed to increased media exposure and indirect loss. Similar results were also reported by Bulut (2006) after an earthquake exposed children.

Demographic variables were also commonly researched in the trauma literature. Most often age, gender, educational and socio-economic status were investigated both in prevalence and in prediction studies (Bulut, 2003; Bulut, 2013). For instance, Braun-Lewensohn et al. (2009) found gender, but not age, as an important contributor. On the other hand, Priebe et al. (2009) and Bulut (2009a) reported that an older age, lower education, and living in a post disaster adversarial condition was significantly associated with higher rates of PTSD.

On May 1, 2003, a 6.4 Richter scale earthquake shook the eastern part of Turkey at 3:27 hours in the morning. It lasted 20 seconds and destroyed a boarding school, killing 83 students and one teacher. It is possible that after such a strong earthquake, children were vulnerable to develop PTSD. Since both the school building and the dormitory collapsed, children were exposed to a variety of adversarial post disaster conditions. Furthermore, the news coverage of the disaster continued for many days. It was repeatedly broadcasted during prime time. Print media outlets also carried extensive coverage of the search and rescue operations. Children in this school experienced a significant and severe stress due to loss of property, loss of their friends, and disruption of their daily routine and educational life. Thus, it was imperative to study the social and organizational help provided and the children's perception of that help.

The purpose of this study was to test the "multidimensional conceptualization of exposure", as it is defined in Braun-Lewensohn et al. (2009). Therefore, it attempted to identify the main contributing effects of the type of exposure on the development of PTSD symptoms in children who have experienced direct, indirect and media exposure to the earthquake disaster and a school building collapse. The contributing effects of objective experiencing and subjective experiencing, direct exposure, indirect exposure, as well as social support, organizational support, education level, and gender's predictive power on the prediction of PTSD, was investigated.

To our knowledge, this is one of the first studies to investigate the different types of exposure and disaster experiences, as well as social and organizational supports' predictive power after major earthquakes and other prolonged and complex traumatic events. Furthermore, this study would shed more light on our understanding of the emergence and 
maintenance of PTSD symptoms in different cultural contexts.

\section{Method}

\section{Participants}

Participants were" disaster survivors" students who were residing in the city of Bingöl, A 6.4 Richter scale earthquake hit the eastern city of Bingöl, in Turkey on May 1, 2003, at 3:27 in the morning. It lasted 20 seconds and destroyed a boarding school, killed 83 students and one teacher.

Data were collected from a large number of students, at both elementary and secondary levels. A total of 270 disaster survivors (68 elementary students $25.2 \%$ and 202 secondary students $74.8 \%$ voluntarily participated in the study. Of those, 71 were female $(26 \%)$ and 199 , male $(74 \%)$. In terms of grade level; there were 43 students from $4^{\text {th }}$ grade $(16 \%)$, 25 from $5^{\text {th }}$ grade $(9.3 \%), 69$ from $6^{\text {th }}$ grade $(25.7 \%), 79$ from $7^{\text {th }}$ grade $(29.4 \%)$, and 53 from $8^{\text {th }}$ grade $(19.7 \%)$. The average age was 10.58 years for the elementary level $(S D=$ 1.18 , range $=8.40-13.40$ ) and 13.43 for the secondary level $(S D=1.44$, range $=11.10-17.40)$ students. Children were asked to fill out a CPTSD Reaction Index, trauma exposure, trauma experiencing, social support, and organizational support scales one year after the disaster.

\section{Instruments}

Children's Post-Traumatic Stress Disorder Reaction Index (CPTSD-RI): The CPTSD-RI is a 20 - item, 4 - point Likerttype self-report scale. It was designed to assess the posttraumatic stress reactions of children between the age range of 6 and 16, who are exposed to different types of traumatic events (Frederick, 1985). CPTSD-RI is the most widely used instrument in the world in the measurement of a range of different kind of traumatic experiences. The CPTSD-RI has good internal consistency and it relates well to clinical diagnosis of PTSD (Yule \& Udwin, 1991). Its composite score indicates the severity of PTSD symptoms. Scores are classified as "mild" (total score of 12 - 24), "moderate" (25 - 39), "severe" (40 - 59) and "very severe PTSD reaction" (above 60). Pynoos (1993) reported that the instruments' severe and very severe categories correctly identified $78 \%$ of the subjects who met the Diagnostic and Statistical Manual of Mental Disorder (DSM), Revised Third Edition criteria for PTSD. The Cohen kappa inter-rater reliability was .87 , which indicates a high inter-item agreement. The CPTSD-RI was translated into Turkish and statistical properties established by Erden, Kiliç, Uslu and Kerimoglu, E. (1999). The Turkish version als demonstrated significant correlations between DSM-IV PTSD criteria and CPTSD-RI scores. Test-retest reliability was found to be .86 and Cronbach alpha internal consistency .75. The scale was also able to capture $80 \%$ of the established DSM IV Edition PTSD cases. For this current studty, the Cronbach alpha internal consistency was found to be .75 for the whole insturment, .71 for re-esperiencing, .68 for avoidance and .65 for hyperarousal sub-dementions. Those figures prove that this insturment is good enough.

In light of the literature and previous studies, a couple of instruments were created in order to investigate the new concepts and test their effectiveness in this research. In conceptualizations of these instruments, theory and previous studies are taken as examples and some of the items, as cited below, are borrowed from their surveys.

Objective Experiences Scale: A 12-item yes or no answerformat questionnaire was specifically developed to investigate children's objective experience of the calamity. Some of the questions were adapted from the Hurricane-Related Traumatic Experience Questionnaire (HURTE; Vernberg et al., 1996). The items focused on the loss and destruction of property and the disruption to participant lifestyles caused by the disasters. For example, children were asked if their house or school is damaged, have they lost any relatives or friends, experienced any water or electric cutoffs, or been separated from their home. For each item, the students indicated whether they were exposed to the aforementioned difficulties. These items are then totaled to create an indicator of objective experience score. The mean score of the objective experiences was $6.92(S D=1.54$ and scores ranged from 0 to 11). The objective experiences scale demonstrated a sufficient reliability of Kuder Richardson $r=.61$.

Subjective Experience (Fear): The subjective experience to the disaster events was assessed through the question of whether or not they felt fear during the earthquakes and collapses.

Social Support Scale (SS): A questionnaire was devised for this study to evaluate the perceived social support. A 10 item yes or no instrument was developed for the children to assess social support. The SS measure was designed to assess to what extent the children perceived any emotional and SS if it was needed. The idea behind the items was to identify if the child perceived that he or she had someone to turn to under stressful conditions. A high score is associated with a greater level of perceived support. Students answered yes (1) and no (0). Items are added to provide a cumulative SS score. The mean score of the SS was 6.43 , (SD $=1.75$ and scores ranged from 0 to 10). Although the scale was short, the Kuder Richardson reliability was $r=.64$ in acceptable range. This instrument is especially develop to tap the earthquake related fears social supports that available for them. The items are created in accordance with the disaster survivor children and adolescents' needs and developmental levels.

Organizational Support Scale (OS): Organizational Support questionnaires consisted of items tapping what children believe regarding governmental and nongovernmental organization and emergency services help for the disaster, which they have experienced, and the readiness level for any anticipated disasters. They answered yes or no and received points for yes answers and those were summed to provide a total organizational support score. This type of measure was not 
utilized in previous disaster research involving children, but in a corporate setting in order to assess the effect of corporate aid regarding employment, coping, and adjustment after disasters (Sanchez et al., 1995). Items are again totaled to provide a cumulative SS score. The mean score of the OS was $3.53,(S D=1.35$ and scores ranged from 0 to 10$)$. SS demonstrated Kuder Richardson reliability of $r=.74$, which is good enough.

Direct Exposure Scale: Participants answered seven yes or no questions concerning their direct exposure, which aimed at identifying students direct and physical first hand exposure experiences. Questions were asked about whether they had seen any dead body, heard anyone died, heard people talk about earthquakes, seen any wounded persons, seen the destroyed places, etc. Items are added to provide a total direct exposure score. The mean score of the SS was 5.21, (SD = 1.21 and scores ranged from 0 to 7). The Kuder Richardson reliability score was $r=.89$.

Indirect Exposure Scale (Media Exposure): This instrument was created to measure a student's indirect and vicarious exposure to the visual, print and auditory exposure, and experiences to the catastrophic events. This scale included three questions aimed at assessing students TV watching, newspaper reading, and radio listening experiences concerning the earthquake related news. Although the scale was short, the Kuder Richardson reliability was $r=.75$. The mean score of the SS was 2.27, (SD =.75 and scores ranged from 0 to 3$)$. The total score of indirect exposure (media exposure) was used as an independent variable in the regression analysis.

\section{Procedure}

The Governorship of Bingöl Province and the Board of Education were contacted, and the intention of this research was explained to them in a written petition that included the survey packages. Upon receiving their permission, consent forms were sent to homes in order to inform children's families of the nature and scope of the study, and permission was requested for the children to participate. The children were also given a consent form, and the purpose of this study, as well as the procedures involved, were explained to them. They were told that participation was voluntary and that confidentiality was guaranteed. They were told that this information would be used to help themselves, and also other children who had experienced similar traumatic events. (as described in more detail in Bulut, 2013).

In the research population, there were approximately 15 students who left some of the instruments blank and five students who were also identified as outliers and not included in the data analysis. A total of 270 students took part in this study. The data set was screened for missing items and checked for the assumption of normality, linearity, and homoscedasticity of the residuals. There was no violation of multicollinearity. All of the requirements were fulfilled for the multivariate regression analysis.
A number of models were tested out for a meaningful explanation of the data. Data was first tested for earthquake experiences and disaster exposure scales. Results did not reveal any interpretable results. Some of the items were subsequently extracted and the other remaining questions left with the instruments. Those items included: if they have had any problems finding food after the calamity, if any of their friends have moved out after the disaster, if they have felt fear during the disaster, and if they have had or have a fear of contagious diseases after the catastrophe.

Finally, contributing factors were predicted with a stepwise regression analysis. A combination of direct and indirect exposure scores, objective and subjective exposure scores, gender, age, organizational, and social support variables were entered into equation in order to predict the PTSD scores.

The purpose of these analyses was to determine whether those variables can predict PTSD symptomatology. Adjusted odds ratios with $95 \%$ confidence intervals were computed from the results of regression analyses. All $p$ - values reported are two-tailed. Statistical significance was set at .05 and analyses were calculated by using SPSS statistical software program.

\section{Results}

Students were exposed to the calamity in direct, physical, repeated and multiple ways. In the aftermath of the earthquake and school building collapse, $94 \%$ of the 270 Turkish youth experienced fear, $92 \%$ reported that their school was destroyed, $59 \%$ said their homes were damaged, $92 \%$ lost a friend, $51 \%$ lost a relative or family member, $78 \%$ experienced water and electric shortage, $38 \%$ food shortage, $79 \%$ saw destroyed automobiles, properties, homes and workplaces, $90 \%$ saw earthquake hit areas, $60 \%$ saw dead bodies, and $88 \%$ saw wounded people. In terms of indirect media exposure, $81 \%$ watched the TV news extensively, $88 \%$ read and saw pictures in print media, and finally $61 \%$ listened to radio news about the disaster.

In each scale, questions were tested for correlations between dependent variables and items were tested for the power size in predicting the PTSD symptoms. There were significant correlations between PTSD total scores and exposure questions of "fear" during the event $(r=.29)$, "having difficulty to find food" $(r=.11)$, afraid of "contagious diseases" $(r=.10)$ and "having a friend who moved out or were separated from friends." Then, three questions were chosen to be included in regression analysis as an independent contributing factor.

In conducting regression analysis, two steps were followed. In the first one, univariate analyses were performed to identify the significant univariate predictors of the variables at hand. Then, significant variables were entered into a multivariate analysis.

Results yielded that all of the aforementioned contributing variables accounted for $17 \%$ of the variance on the PTSD total scores. Direct exposure $6 \%$, subjective experi- 
ences (fear) $5.4 \%$, having a friend who moved away $2.6 \%$, age (and educational level) $2 \%$, and food shortage $1 \%$ explained the total variance.

The beta weights show that direct exposure, subjective experiences, age, having a friend moving out, and food shortage made a slight contribution to the results. The combination of independent variables significantly predicted PTSD scores one year after the calamity, $F(1,268)=17.108$, $p<.001$. The adjusted $\mathrm{R}$ squared value was .17 , which indicates that $17 \%$ of the variances on the PTSD scores were explained with this current model. The Effect size is measured with R Square Change, .012 which indicated a somehow small-medium effect size. Overall, the explained variance of PTSD in the model was $17 \%$. Obviously, this indicates there are other variables to account for the unexplained variance in the model at hand.

Table 1. Stepwise regression analysis for the predictors factors on the PTSD total score.

\begin{tabular}{|c|c|c|c|c|c|c|c|}
\hline Variable & $\mathrm{B}$ & $\begin{array}{l}\text { Standard } \\
\text { Error B }\end{array}$ & $\beta$ & $t$ & $p$ & $\begin{array}{l}\text { Zero-order } \\
\text { correlation }\end{array}$ & $\begin{array}{c}\text { Partial } \\
\text { correlation }\end{array}$ \\
\hline Constant & 23.14 & 4.17 & & 5.55 & .000 & & \\
\hline Direct Experience & 2.311 & .56 & 232 & 4.10 & .000 & .26 & .25 \\
\hline $\begin{array}{l}\text { Subjective } \\
\text { Experience } \\
\text { (fear) }\end{array}$ & 11.18 & 2.78 & 226 & 4.02 & .000 & .23 & .24 \\
\hline Age/educational level & -4.11 & 1.57 &,- 149 & -2.62 & .009 & -.17 & -.16 \\
\hline Food shortage & 2.92 & 1.40 &, 118 & 2.08 & .039 & .15 & .13 \\
\hline Friends moved out & 2.84 & 1.43 & ,112 & 1.99 & .048 & .13 & .12 \\
\hline
\end{tabular}

$\mathrm{R}=.411, \mathrm{R}^{2}=.169, p<.05$

$F(1,268)=17.108, p=.000$

The Effect size is measured with R Square Change, .012 which indicated a somehow small-medium strength.

Surprisingly, gender, physical exposure, indirect (media) exposure, social support, and organizational support did not have any significant effect on the result.

Furthermore, participants were compared for the gender variable with univariate ANOVAs on the set of the independent variables. In terms of social support, organizational support, PTSD total score, indirect exposure, direct exposure, trauma experiences, and subjective experiences, male and female students did not show any significant differences. There were no significant differences in the male and female student responses for this particular group of children.

Children were also compared for age (and educational level) for the same variables. Students were significantly different in their scores for organizational support $F(1,268)=$ 18.23, $p<.05$ and PTSD total scores $F(1,268)=8.35, p<$ .05 . In both independent variables, students in elementary education outscored the middle school students and this reached the significance level. It seems that younger students are more vulnerable to traumatic events, but they also perceived more organizational support.

\section{Discussion}

Community psychologists need to be cognizant regarding the specific context of a trauma and the cultural texture of the affected society. School counselors and psychologists also need to take into account risk and protective factors when they are involved in the treatment, intervention, and prevention of post traumatic stress symptoms. The findings of this present study revealed that subjective exposure (fear) and direct exposure were the most significant contributors of the PTSD total scores, which is in line with the previous studies. Similarly, supporting this current research, Zhang et al. (2011) and Wang et al., (2009) also reported initial fear and intensity of exposure as a most predictive factors. For example, Braun-Lewensohn et al. (2009) found subjective exposure to be the most important contributing factor for adolescents. In the same fashion, Tuicomepee and Romano (2008) reported that with tsunami experiences, age and gender are the main contributing factors for Thai adolescents.

In previous studies, direct exposure has been repeatedly mentioned as the primary source of the psychological stress. Kim et al. (2009) compared direct and indirect exposure groups and concluded that direct exposure groups have had more PTSD and other psychological problems. Wang et al., (2009) also conducted a case control study with Chinese adult survivors of the earthquake and found the strong direct effect of being in epicenter even 3 years after the calamity. Likewise, Bulut et al. (2005) looked at the prevalence rates of high and low impact groups and Bulut (2006) looked at directly exposed and non-exposed groups' prevalence rates of PTSD. Results unanimously show that direct exposure is a significant contributor in the traumatic reactions as well as other mental health problems.

Conversely, in this study, media exposure, gender, objective and physical exposure seemed to be very poor predictors of a child's post traumatic stress reactions. Similar results were also reported in a study by Braun-Lewensohn et al. (2009), in which objective exposure only accounted for $3 \%$ of the variance. In the same study, in contrast to previous research, they found a negative relationship between media exposure and mental health problems. They argue: "The more adolescents consulted media, the less they experienced mental health problems." In a similar study involving American children's TV exposure to terrorist attacks, Pfefferbaum et al. (2001) reported extensive TV viewing, but small corresponding effects of TV exposure to the post traumatic stress reac- 
tions. They caution that maybe it is vice versa in a way that stressed out children tend to watch more TV news. Furthermore, the Pfefferbaum et al. (2003) study of indirect interpersonal exposure to the Oklahoma City bombing reported that print media exposure was more strongly associated with lasting post traumatic stress than TV watching.

On the other hand, Otto et al. (2007) investigated children who indirectly witness terror attacks via TV viewing; they concluded that the amount of TV viewing increases the risk of developing PTSD reactions. In their study, a small portion of children (5,4 \%) developed PTSD symptoms as a result of TV watching. It seems that even only media viewing of traumatic events is sufficient to produce PTSD symptoms in susceptible individuals. They found a linear correlation between TV viewing and PTSD sympthomatology. However, the current study at hand did not find any significant relationship between indirect media exposure and PTSD. Indirect media exposure only accounted for $1 \%$ of the variance, but this did not reach the significant level. In contrast to this study, and in supporting this current study, BraunLewensohn et al. (2009) found a reverse relationship. For the present study, one possible explanation could be that since these children have already experienced all of the hardships of the catastrophic event first hand, watching TV or reading newspaper articles about the events did not affect them. Essentially, they were already traumatized by the actual events. Post disaster averserials called "secondary traumatization" and children in this current study have experienced multiple and prolonged adversarial conditions, that means they have already experienced the disaster in full-fledged way; therefore, the effects of trauma and ptsd rates was very high (Bulut, 2009, 2010, 2013)

While school and home damage, relative or friend's death, gas, water and electric shortage did not significantly contribute to the results, fear during the disaster, food shortage and having a friend moving out after the earthquake were all powerful predictors.

Even though subjective experience (fear) explained only a small proportion of the variance in this study, previous studies repeatedly reported the instrumental role of fear in the etiologies of PTSD. For example, in the Laufer and Solomon (2006) study, fear was the strongest predictor factor of post traumatic symptoms. Likewise, Braun-Lewensohn et al. (2009) and Wang et al. (2009) also cited the subjective experience (fear) as the most important contributor to the adolescents' PTSD stress. Furthermore, Gavriovic et al. (2002) also reported similar findings. Individual subjective perception and appraisals of the traumatic events, their feelings of fear, helplessness, or hopelessness are detrimental factors in the development of PTSD reactions. Nevertheless, as it has been seen here, children and adolescents fear was not as high as it would perhaps be expected. This may be because the disaster hit the city in the middle of the night and the children did not actually experience the incidents, but instead experienced the after effects. This discussion will also go to the DSM-IVTR criteria A, which requires actual events, desperate feel- ings, threat to life, and threat to the lives of loved ones during the incidence.

Demographic variables including age and educational level were taken together since the participants were grouped by elementary and secondary school. Thus, it was naturally possible to investigate the effects of age and educational level together. Surprisingly, age (and educational level) had a very slight effect $(2.6 \%)$ on the results. Likewise, other studies also investigated the possible effect of age on PTSD symptoms. Braun-Lewensohn et al. (2009) investigated the relationship of age (younger, middle, and older adolescents) and PTSD reactions. They did not find any significant correlation with PTSD scores and other mental and emotional problems. Older adolescents were however found to be more vulnerable to PTSD than their younger counterparts. In the same study, they also found that older adolescents demonstrated more subjective experience (fear) than did the younger children. Similarly, in the Priebe et al. (2009) study with adults who had been in civil conflicts in former Yugoslavia, and Zhang et al. (2011) study with Chinese earthquake survivors, older age and lower educational level was more closely associated with PTSD. It was postulated that higher education prepares individuals to develop more effective strategies and protect themselves against adverse conditions. In the same study, they found that survivors who moved out of the place in which traumatic experiences occurred demonstrated better recovery levels than those who remained living in the same place.

For Chinese earthquake survivors, Wang et al., (2009) and Zhang et al. (2011) listed female gender, lower educational level, being ethnic minority and lower social support as risk factors. People with low education; have lower resilience, poor coping skills, low self-esteem and poor insights that made difficult recovery for survivors. These results are also applicable to this current study, with the exception that younger students (younger age and lower educational level) seemed to be more traumatized in this study than older ones. Similar to the previous study, survivors who had to continue living in the same city experienced all of the negative post disaster adversarial conditions. Similar results were also reported in Bulut's (2003) earthquake study; children manifested both physical and psychological avoidance and did not want to go to places that reminded them of the disaster.

While Cheng et al. (2014) and Zhang et al. (2011) reported being a female gender as a strong risk factor, BraunLewensohn et al. (2009) found gender to be a small contributing factor $(10 \%)$. However, Laufer and Solomon (2006) argued that gender was not a direct predictor of PTSD (3 $\%$ ), but an indirect predictor via the effects of fear of which female students demonstrated more fear symptoms. In our study, gender differences were not found in the mean scores of the independent variables, including the PTSD total scores. On the other hand, March et al. (1997) found a significant effect of gender on PTSD. Females were more likely to develop PTSD, then their counterparts. Unfortunately, in this present study gender did not seem to have any effect on 
the results. It only had a $1.1 \%$ contribution and that was not significant. This may be because this particular school was a boarding school; thus, the majority of the participants were male, and only a quarter of them were female students. Another explanation could be that, since this was a very large catastrophic event, male and female students were expected to be affected equally, because they were subject to the same incidents and post disaster adversarial effects. In fact, this was tested in this study and it was found that girls and boys did not differ in any of the independent variables.

Food shortage only explained $1 \%$ of the total variance. Even though this is a very small contribution, it was reported in other studies as well. For example, Seino et al. (2008) reported the experience of food shortage as an independent contributor for PTSD for people in Afghan civil disturbances. It can be speculated that even though children went through harsh living conditions, they were provided enough food, so that they were not deprived of it. Therefore, this did not have any effect on the model that is currently being tested.

Social support did not have any predictive power in regression analysis. There were also no gender differences in ANOVA comparison. However, Cheng et al. (2014) and Zhang et al. (2011) cited social support as among one of the most important protective factors against PTSD. Martin, March, Boyer and Martin (2009) mentioned receiving social support as a significant protective factor during the traumatic event. Tuicomepee and Romano (2008) mentioned family functioning and Otto et al. (2007) pre-event family support as protective factors. Although there are many studies that support the positive effect of social support, this was not confirmed in this research. It seems very paradoxical that Turkish culture is a collectivistic and very community oriented but social support did not have a protective effect. Then it can be postulated that cultural differences may also play a role in moderating the PTSD symptoms.

Regarding organizational support, even though this variable did not have any significant effect on the prediction of

\section{References}

American Psychiatric Association (2000). Diagnostic and Statistical Manual of Mental Disorders (Rev. $4^{\text {th }}$ ed.). Washington, D.C.: American Psychiatric Association.

Bados, A., Greco, A. \& Toribio, L. (2012). Traumatic experiences and posttraumatic stress disorder in Spanish university students. Anales de Psicologia, 28(2), 387-396. 387-396 doi:10.6018/analesps.28.2.148861

Başoğlu., M, Kiliç., C, Salcioğlu., E., \& Livanou M.(2004). Prevalence of posttraumatic stress disorder and comorbid depression in earthquake survivors in Turkey: An epidemiological study. Journal of Traumatic
Stress.
2004
Apr;
$17(2)$
133-41. doi:10.1023/B:JOTS.0000022619.31615.e8

Braun-Lewensohn, O., Clestin-Westreich, S., Clestin, L. P., Verté, D., \& Ponjaert-Kristoffersen, I. (2009). Adolescents' mental health outcomes according to different types of exposure to ongoing terror attacks. Journal of Youth and Adolescence, 38, 850-862.

Bulut, S. (2003). Underlying dimensions and prevalence of Post Traumatic Stress Disorder among $4^{\text {th }}$ and $5^{\text {th }}$ grade children who experienced the 1999 Turkish earthquakes. Doctoral dissertation, Oklahoma State University, Stillwater, OK, USA. International Dissertation Abstracts.
PTSD symptoms, a very large number of students indicated that they were very satisfied with the help and approach of civic and voluntary organizations, such as Red Crescent, etc. They also believed that these voluntary and governmental organizations were well prepared for the anticipated future earthquakes. Sanchez et al. (1995) emphasized the financial and instrumental help of the cooperates and Cheng et al. (2014) mentioned having a regular income and providing job opportunities for survivors after the disasters. Similarly, Kun et al. (2009) reported the importance of governmental and nongovernmental programs for the social and economic supports as it has been also recommended in other studies.

In conclusion, it appears that protective factors can strengthen or modify the individuals coping skills. As it had been discussed above, healthy family functioning, as well as support from peers and family members, can reduce the stress level an individual may experience. On a community level, organizing a social network by using civil organizations may help people to establish the sense of social belongingness and connectedness, which eventually helps them to keep their emotional and mental health intact.

In addition to early intervention and treatment, survivors need to be monitored for the long-term effects of disaster. Furthermore, school and community based treatment approaches should be for considered quick and cost-effective services for child and adolescent.

There are also some limitation of this study worth to mention here. First of all, the data was collected with selfreport instruments. This may not exactly tap the traumatic reactions. For more accurate diagnosis clinical interviews are needed, which was not possible because of time strain. Furthermore, since this was a boarding school the overwhelming majority of the participants were boys. They may be overly represented in sample. Additionally, some of the instruments is formed for this study and the psychometric properties are not established for the Turkish adolescents population.

Bulut, S., Bulut, S., \& Taylı, A. (2005). The dose of exposure and prevalence rates of Posttraumatic Stress Disorder in a sample of Turkish children eleven months after the 1999 Marmara earthquakes. School Psychology International, 26(1), 55-70.

Bulut. S. (2006) Comparing the earthquake exposed and non-exposed Turkish children's post traumatic stress reactions. Anales de Psicologia, 22(1), 29-36

Bulut, S. (2009a). Comparing children posttraumatic stress reactions in terms of age and gender after an earthquake. Turkish Psychological Counseling and Guidance Journal, 4(31), 43-51.

Bulut, S. (2009b). Factor analysis of posttraumatic stress disorder in children experienced earthquakes in Turkey. Contemporary Psychology, 12(2), 407-424.

Bulut, S. (2010). Children's posttraumatic stress reactions and subsymptoms: Three years of longitudinal investigation study after a direct exposure to an earthquake and school's collapse. Turkish Journal of Psychology, 25(66), 87-100.

Bulut, S. (2013). Prediction of post traumatic stress Symptoms via comorbid disorders and other social and school problems in earthquake ex- 
posed Turkish adolescents. Revista Latinoamericana de Psicología, 45(1),4761.

Cheng, Y., Wang, F., Wen, J. \& Shi, Y. (2014). Risk factors of posttraumatic stress disorder (PTSD) after Wenchuan earthquakes: A case control study. PLOS ONE, 9(5), 1-7. e96644 www.plosone.org

Erden, G., Kiliç, E. Z., Uslu, R. I., \& Kerimoglu, E. (1999). The validity and reliability study of the Turkish version of child post traumatic stress reaction index. Turkish Journal of Child and Adolescent Mental Health, 6(3), 143-9.

Frederick, C. J. (1985). Children traumatized by catastrophic situations. In: Eth S, Pynoos R. S, ed. Post-Traumatic Stress Disorder in children. Washington, D.C.: American Psychiatric Press.

Freedy, J. R., Saladin, M. E., Kilpatrick, D. G., Resnick, H. S., \& Saunders, B. E. (1994). Understanding acute psychological distress following natural disaster. Journal of Traumatic Stress, 7(2), 257-273.

Garrison, C. Z., Bryant, E., Addy, C. L., Spurrier, P. G., Freedy, J. R., \& Kilpatrick, D. (1995). Posttraumatic stress disorder in adolescents after Hurricane Andrew. Journal of American Child and Adolescent Psychiatry, 34, 1193-1201. DOI: https://doi.org/10.1097/00004583199509000-00017

Gavriovic, J., Lecic, T. D., Knezevic, G., \& Priebe, S. (2002). Predictors of post traumatic stress in civilians one year after air attacks: A study of Yugoslavian students. Journal of Nervous and Mental Disease, 190, 257-262.

Habigzang, L. F., Freitas, P. P. C., Hohendorff, J. V., \& Koller, S. H., (2016). Cognitive-behavioral group therapy for girls victims of sexual violence in Brazil: Are there differences in effectiveness when applied by different groups of psychologist? Effectiveness of group therapy for girls victims of sexual violence. Anales de Psicologia, 32(2), 433-440. doi:10.6018/analesps.32.2.213041

Heetkamp, T. \& de Terte, I. (2015). PTSD and Resilience in Adolescents after New Zealand Earthquakes. New Zealand Journal of Psychology, 44(1), 31-38.

Kim, B. N., Kim, J.W., Kim, H. W., Shin, M. S., Cho, N. H., \& Ahn, H. et al. (2009). A six-month follow-up study of post traumatic stress and anxiety/depressive symptoms in Korean children after direct or indirect exposure to a single incident of trauma. Journal of Clinical Psychiatry, 70(80), 1148-1154.

Kun, P., Han, S., Chen, X., \& Yao, L. (2009). Prevalence and risk factors for post traumatic stress disorder: a cross-sectional study among survivors of the Wenchuan 2008 earthquake in China. Depression and Anxiety, 26(12), 1134-1140.

LaGreca, A., Silverman, W. K., Vernberg, E. M. \& Prinstein, M. J. (1996) Symptoms of posttraumatic stress in children after hurricane andrew: A Prospective Study, Journal of Consulting and Clinical Psychology 64(4),71223. doi:10.1037/0022-006X.64.4.712

Laufer, A., \& Solomon, Z. (2006). Posttraumatic Symptoms and Posttraumatic Growth Among Israeli Youth Exposed to Terror Incidents. Journal of Social and Clinical Psychology, 25 (4), 447.https://doi.org/10.1521/jscp.2006.25.4.429

Leiva-Bianchi, M. C. \& Gallardo, I. (2013). Validation of the short posttraumatic stress disorder rating interview (SPRINT-E) in a sample of people affected by F-27 Chilean earthquake and tsunami. Anales de Psicologia, 29(2), 328-334. doi:10.6018/analesps.29.2.130681

Maia, L. A. C. R. (2010). Neurobiyological basis of Post-Traumatic Stress. Anales de Psicologia, 26(1), 1-10.

March, J. S., Amaya-Jackson, L., Terry, R., \& Costanzo, P. (1997). Post traumatic symptomatology in children and adolescents after an industrial fire. Journal of American Academy of Child and Adolescent Psychiatry, 36(8), 1080-1088.

Martin, M., March, A., Boyer, R., \& Martin, N. (2009). Predictors of the development of post traumatic stress among police officers. Journal of Trauma and Dissociation, 10(4), 451-468.

Otto, M. W., Henin, A., Hirshfeld-Becker, D. R., Pollack, M. H., Biederman, J., \& Rosenbaum, J. F. (2007). Post traumatic stress disorder symptoms following media exposure to tragic events: impact of 9/11 on children at risk for anxiety disorders. Journal of Anxiety Disorder, 21(7), 888-902.

Pfefferbaum, B., Seale, T. W., McDonald, N. B., Brandt, E. N., Rainwater, S. M., \& Maynard, B. T. et al. (2000). Post traumatic stress two years after the Oklahoma City bombing in youths geographically distant from the explosions. Psychiatry, 63(4), 356-370.

Pfefferbaum, B., Nixon, S. J., Tivis, R. D., Doughty, D. E., Pynoos, R. S., \& Gurwitch, R. H. et al. (2001). Television exposure in children after a terrorist incident. Psychiatry, 64(3), 202-211.

Pfefferbaum, B., Seale, T. W., Brandt, E. N., Pfefferbaum, R. L., Doughty, D. E., \& Rainwater, S. M. (2003). Media exposure in children one hundred miles from a terrorist bombing. Annals of Clinical Psychiatry, 15(1), $1-8$.

Pfeferbaum, B. J. (2005). Aspects of exposure in childhood trauma: the stressor criterion. Journal of Trauma and Dissociation, 6(2), 17-26.

Priebe, S., Matanov, A., Gavrilovic, J. J., McCrone, P., Ljubotina, D., \& Knezevic, G. et al. (2009). Consequences of untreated post traumatic stress disorder following war in former Yugoslavia: Morbidity, subjective quality of life, and care costs. Croatian Medical Journal, 40, 465-475.

Pynoos, R. S. (1993). Traumatic stress and developmental psychopathology in children and adolescents (pp. 205-239). In J. M. Oldham, M. B. Riba and A. Tasman (Eds.), Review of Psychiatry, Vol. 12, Section II. Washington, D.C.: American Psychiatric Press Inc.

Rubonis, A. V. \& Bickman, L. (1991). Psychological impairment in the wake of disaster: The disaster-psychopathology relationship. Psychological Bulletin, 109(3), 384-399.

Ruiz, S. R. S. (2006). Longitudinal evaluation of the effects of posttraumatic stress after an industrial catastrophe. A case of San Juan Ixhuatepec Community (Mexico). Anales de Psicologia, 22(1), 22-28.

Sanchez, J. I., Korbin, W. P., \& Viscarra, D. M. (1995). Corporate support in the aftermath of a natural disaster. Academy of Management Journal, 38(2), 504-515.

Seino, K., Takano, T., Mashal, T., Helmat, S., \& Nakamura, K. (2008). Prevalence of and factors influencing posttraumatic stress disorder among mothers of children under five in Kabul Afghanistan, after decades of armed conflicts. Health Quality Outcomes, 23, 6-29.

Terranova, A. M., Boxer, P., \& Shefield-Morris, A. (2009). Factors influencing the course of post traumatic stress following a natural disaster: Children's reactions to hurricane Katrina. Journal of Applied Developmental Psychology, 30, 344-355.

Tuicomepee, A., \& Romano, J. L. (2008). Thai adolescent survivors one year after the 2004 tsunami: A mixed methods study. Journal of Counseling Psychology, 55(3), 308-318.

Vernberg, E. M., La Greca, A. M., Silverman, W. K., \& Prinstein, M. J. (1996). Predication of post traumatic stress symptoms in children after hurricane Andrew. Journal of Abnormal Psychology, 105, 237-248.

Vila, G., Porche, L. M., \& Mouren-Simeoni, M. C. (1999). An 18-month longitudinal study of post traumatic disorder in children who were taken hostage in their school. Psychosomatic Medicine, 61(6),746-754.

Wang, L., Zhang, Y., Wang, W., Shi, Z., Shen, J., Li, M., et al. (2009). Symptoms of posttraumatic stress disorder among adult survivors three month after the Sichuan earthquakes in China. Journal of Traumatic Stress, 22(5), 444-450. doi:10.1002/jts.20439

Wolfe, D. A., Sas, L., \& Wekerle, C. (1994). Factors associated with the development of post traumatic stress disorder among child victims of sexual abuse. Child Abuse and Neglect, 18, 37-50.

Wu, C. H., Chen, S. H., Wenig, L. J., \& Wu, L. C. (2009). Social relations and PTSD symptoms: A prospective study on earthquake-impacted adolescents in Taiwan. Journal of Traumatic Stress, 22(5), 451-459.

Yule, W., \& Udwin, O. (1991). Screening child survivors for post traumatic stress disorders: Experiences from the "Jupiter" sinking. British Journal of Clinical Psychology, 30, 131-138.

Zhang, Z., Shi, Z., Wang, L. \& Liu, M. (2011). One year later: Mental health problems among survivors in hard-hit areas of the Wenchuan earthquake. Public Health, 125, 293-300. doi:10.1016/j.puhe.2010.12.008

(Article received: 01-12-2016; revised: 08-02-2017; accepted: 25-04-2017) 